\title{
TRATAMENTO DA NEUROCISTICERCOSE COM PRAZIQUANTEL
}

\author{
L. G. VIANNA*- V. MAOEDO**-P. MELLO*- H. A. O. SOUZA*** \\ J. M. $\operatorname{COSTA} * * * *$
}

\begin{abstract}
RESUMO - 27 pacientes com neurocisticercose foram tratados com praziquantel, utilizado em doses progressivamente crescentes até alcançar $50 \mathrm{mg} / \mathbf{k g} /$ dia, por periodo de 21 dias, associado a dextametasona. Os doentes foram avaliados clínica e laboratorialmente durante o tratamento e, aqueles que completaram um ano de evolução, repetiram os testes imunofluorescência e ELISA neste período. Cefaléia foi o sintoma encontrado mais freqüentemente durante o tratamento, ocorrendo em 37\% dos pacientes; $18,5 \%$ dos doentes apresentaram nipertensāo intracraniana, um deles evoluindo para o óbito; $\mathbf{2 5 , 9 \%}$ dos enfermos tiveram que suspender o praziquantel antes de completar o tratamento, devilo ao surgimento de compli. caçōes importantes. Nos exames laboratoriais realizados no sétimo dia de tratamento, 33,3\% dos pacientes apresentaram anormalidades, sendo leucocitose a mais frequiente. No periodo de um ano, $72,2 \%$ dos enfermos tiveram melhora do quadro clínico, enquanto os testes imunológicos tornaram-se não-reagentes no soro em 45,4\% dos doentes e no LCR em 42,8\%. Entretanto, nem sempre houve coincidência da melhora clínica com a apresentação dos testes imunológicos nāo-reagentes. No presente trabalho, năo é possível afirmar que os testes imlnológicos nāo-reagentes, assim como a melhora clínica dos pacientes, sejam consequỉentes à eficácia do tratamento com o praziquantel. Devido à grande freqüência e gravidade dass complicações deste tratamento, os pacientes devem ser avaliadus individualmente quanto aos riscos versus os beneficios dele.
\end{abstract}

\section{Treatment of neurocysticercosis with praziquantel}

SUMMARY - Twenty seven patients with neurocysticercosis were treated with praziquante] in progressive doses reaching $50 \mathrm{mg} / \mathrm{kg} /$ day associated with dexamethasone for 21 days. The patients were followed during and after treatment and those followed up for one year repeated their immunological tests (indirect immunofluorescence and ELISA) at this time. Headache was the most frequent symptom during the treatment, occurring on $37 \%$ of patients. During the treatment $18.5 \%$ of patients had intracranial hypertension and one died. One year after treatment $72.2 \%$ of patients who finished treatment improved. The imminological tests became negative in $45.4 \%$ of patients sera and $42.8 \%$ of cerebrospinal fluids. There was no correlation between the clinical evolution and immunological tests. In this study it is not possible to afirm that both negative immunological tests and good clinical evolution were consequents to the efficacy of praziquantel treatment. Due to the great frequency and seriousness of this treatment complications, the patients with neurocysticercosis must be individually evaluated to know the risks and the benefits of the treatment with praziquantel.

Trabalho realizado no Núcleo de Medicina Tropical e Nutriçăo, Universidad€ de Brasília: *PhD, Professor Adjunto da Faculdade de Ciências da Saúde (FCS), Universidade de Brasilia; ** Professor Titular da FCS; *** Médico Residente do Hospital de Base do DF; **** Professor Adjunto da Faculdade de Medicina de Uberlândia. Resumo dos resultados foi publicado anteriormente.

Dra. Lucy Gomes Vianna - Faculdade de Ciencias da Sanide, Departamento de Clinica Médica, Universidade de Brasilia - Campus Universitario, Asa Norte - 70919 Brasília DF - Brasil. 
A cisticerose é doença complexa, que envolve intrincada relação hospedeiro-parasito, constituindo problema de saúde pública em vários paises em desenvolvimento. Não se dispunha de tratamento quimioterápico eficaz para a cisticercose humana até 1972. Neste ano, foi descoberto que o praziquantel, derivado da classe quimica das isoquinoleinas heterocíclicas, apresentava atividade anti-helmíntica 12 . Foi confirmada a eficácia curativa desse composto contra ampla gama de platelnintos, incluindo-se as classes trematódea e cestóidea. Thomas em 197720 , Chavarria e González em 19783 e Thomas e col. em 198121 demonstraram, em estudos in vitro assim como em infecções experimentais e naturais, que o praziquantel era eficaz contra cisticercos de numerosas espécies de cestóideos, incluindo infecçōes por Cysticercus cellulosae em porcos. As primeiras publicações sobre o uso do praziquantel em pacientes com neurocisticercose foram feitas, em 1980, por Robles e Chavartia no México 16, Spina-França e Nóbrega no Brasil 18 e Rim e col. na Coréia 15. Desde então vários trabalhos, a maioria relatos de casos isolados ou estudos não-controlados, avaliaram a eficácia dessa medicação em doentes com neurocisticercose $1,2,5,7,11,12,16,18,19$.

$O$ presente estudo teve como objetivos investigar os efeitos colaterais do praziquantel durante tratamento de pacientes com neurocisticercose, assim como a tolerabilidade e eficácia desta droga.

\section{MATERIAL E METODOS}

Foram tratados com praziquantel 27 pacientes com neurocisticercose, 10 do sexo masculino e 17 do feminino, com média de idade de 25,9 anos (13 a 52 anos). A doença loi confirmada: em 20 pacientes por apresentarem os testes imunofluorescência indireta (RIF) $e$ imuno-enzimático (ELISA) reagentes no líquido cefalorraquiano (LCR); em 7 por mostrarem imagens císticas na tomografia computadorizada de crânio (TC). A RIF foi executada seguindo a padronização de Machado e col. 14. A ELISA foi realizada segundo a metodologia de Costa 6 , empreganao-se como antigeno o extrato salino total do cistícerco.

o praziquantel foi utilizado na dose de $16 \mathrm{mg} / \mathrm{kg} / \mathrm{dia}$ nos três primeiros dias, 32 $\mathrm{mg} / \mathrm{kg} / \mathrm{dia}$ nos três dias subseqentes e $50 \mathrm{mg} / \mathrm{kg} / \mathrm{dia}$ a partir do sétimo dia até completarem-se 21 dias de tratamento,dividido em três tomadas diárlas 19. Em 6 pacientes com hidrocefalia que haviam implantado válvula de derivação ventriculo-peritoneal, tipo Holter com pressão média, foi empregada a dose de $50 \mathrm{mg} / \mathrm{kg} /$ dia desde o primeiro dia de tratamento. Todos os doentes usaram, concomitantemente, dexametasona na dose de $12 \mathrm{mg} / \mathrm{dia}$ nos adultos e $0,25 \mathrm{mg} / \mathrm{kg} / \mathrm{dia}$ nas crianças. O corticóide foi introduzido no dia anterior ao do inicio do praziquantel. Um doente, examinado na fase preliminar do estudo, desenvolveu crises epilépticas e hipertensāo intracraniana uma semana após a suspensão concomitante do praziquantel e da dexametasona. Por este motivo, o corticóide foi mantido nog demais enfermos até 7 dias após a suspensão do praziquantel, sendo nesta última semana utilizado em doses p̆rogressivamente decrescentes. Foram tratados adequadamente, antes do inicio da dexametasona, aqueles pacientes que apresentaram parasitos, excetuada a tênia, no exame de rezes.

Os doentes foram acompanhados laboratorialmente durante o tratamento, realizando nos dias $0,7^{\circ}$ e $15^{\circ}$ os seguintes exames: hemograma completo, velocidade de hemossedimentaçăo, proteinas totais e fraçoses, provas de homeostasia (tempo de coagulação, sangramento e contagem de płaquetas), provas de função hepática (transaminases pirúvica e oxalacética, fostatase alcalina, tempo de protombına), provas de função renal (uréia, creatinina), dosagem de eletrólitos (sódio, potássio, cloro), glicemía, colesterol, exame de urina (elementos anormais e sedimento) e eletrocardiograma. Durante a vigência do tratamento, foram realizados diariamente exames clínicos em todos os pacientes, invegtigando-se cuidadosamente quanto ao surgimento de qualquer sintoma ou sinal físico. Os testes imunológicos RIF e ELISA foram repetidos, um ano após o tratamento, no soro de 11 pacientes e no LCR de 7 .

\section{RESULTADOS}

Na tabela 1 estão listadas as manifestaçōes clínicas surgidas durante o tratamento com praziquantel, associado à dexametasona, nos 27 doentes com neurocisticercose. A cefaléia foi o sintoma mais frequientemente encontrado, ocorrendo em 10 pacientes (37\%); 5 doentes $(18,5 \%)$ desenvolveram hipertensão intracraniana, sendo que dois deles tiriham previamente sido submetidos a derivação ventrículo-peritoneal. Um desses doentes apresentou cefaléia, crises epilépticas e confusão mental no primeiro dia do tratamento, logo após a ingestão da segunda dose da medicação. o praziquantel foi suspenso nesses 5 pacientes. O tutal de 7 enfermos (25,9\%) suspenderam o praziquantel antes de completar o tratamento, devido ao surgimento das seguintes complicacões: hipertensão intracraniana (em 5), psicose aguda e urticária (em 
- polifagia

— tonturas, insônia, astenia

- epigastralgia, vômitos

- edema de papilıa

- confusão mental

- convulsôes, taquicardia, mialgia, anorexia, aumento de peso

- turvação visual, diarréia, dor abdominal, sensaçăo de frło, descamação da pele, sindrome de Cushing, conjuntivite viral, dispnéia

- diplopia, parestesias, xerostomia, prurido nasal, urticária, acne, soluços, disfagia, pirose, emagrecimento, retenção hídrica, hipertensão arterial, psicose, sonolência, polaciúria, sensaçăo de calor, herpes-zóster

Tabela 1 - Manifestacbes clinicas surgidas durante o tratamento com praziquantel, associado a dexametasona, em zy pacientes com neurocisticercose.

1) e aumento das transaminases (em 1). Os exames laboratoriais mostramam-se normais antes do inicio do tratamento com o praziquantel; 9 pacientes $(34,3 \%)$ apresentaram anormalidades nos exames realizados no 70 dia de tratamento, que se mantiveram nos exames do 15 dia. Estas alteracóes foram: leucocitose em 7 doentes $(25,9 \%)$, aumento das transaminases oxalacética e pirúvica em $1(3,7 \%)$ e aumento da desidrogenase lática em 1 (3,7\%). Somente um dos enfermos que desenvolveu leucocitose apresentou infeccão bacteriania associada. O doente que mostrou aumento das transaminases tinha sido alcólatra até 5 anos antes. Surgiu taquicardia sinusal no eletrocardiograma de 1 paciente $(3,7 \%)$. Dois enfermos (7,4\%) evoluiram para o óbito durante o tratamento, tendo como causa-mortis hipertensão intracraniana e choque séptico, respectivamente. O primeiro paciente mostrou, antes do tratamento, TC com numerosos cistos não alterados por administração do meio de contraste e os testes imunológicos reagentes no LCR. Neste doente, o praziquantel e a dexametasona foram suspensos no $10 \%$ dia de tratamento, devido a surgimento de conjuntivite viral. Uma semana após, o paciente faleceu na vigência de estado de mal epiléptico.

Na tabela 2 é mostrada a evolução clínica dos 18 pacientes que completaram o tratamento, um ano após seu término, correlacionada a forma clínica da doenca. Foram conside-

Evolução clínica

Forma clínica da

$\begin{array}{llll}\text { inalterada } & \text { melhora } * & \text { piora } & \text { total } \\ \text { no } \% & \text { no } \% & \text { no } \% & \end{array}$

neurocisticercose

no $\%$

no $\%$

n $\%$

no

\begin{tabular}{|c|c|c|c|c|c|c|c|}
\hline Epiléptica & 1 & 12,5 & 7 & $87,5(a)$ & - & 一 & 8 \\
\hline $\begin{array}{l}\text { Hipertensiva } \\
\text { (com hidrocefalia) }\end{array}$ & 1 & 16,7 & 3 & $50,0(b)$ & 2 & 33,3 & 6 \\
\hline $\begin{array}{l}\text { Hipertensiva } \\
\text { (pseudotumoral) }\end{array}$ & - & - & 2 & 100 (c) & - & - & 2 \\
\hline Psiquica & - & - & 1 & $50,0(d)$ & 1 & 50,0 & 2 \\
\hline Total & 2 & 11,1 & 13 & 72,2 & 3 & 16,7 & 18 \\
\hline
\end{tabular}

Tabela $2-$ Evoluçâo clínica de 18 pacientes com neurocisticercose, correlacionada a forma clinica da doenca, um ano apbs o tratamento com praziquantel. NS, não significante. * Diferenca entre: (a) e (b), NS; (a) e (c), NS; (a) e (d), NS; (b) e (c), NS; (b) $e$ (d), NS; (c) $e$ (d), NS. 
rados melhorados aqueles doentes que apresentaram regressăo parcial ou total de sua sintomatologla: 13 enfermos $(72,2 \%)$ tiveram melhora do quadro clínico, sendo 7 (53,8\%) com a forma eplléptica (em um deles associada a hemiplegia), 3 (23,1\%) com a forma hidrocefálica, $2(15,4 \%)$ com a forma pseudotumoral e $1(7,7 \%)$ com sintomas psíquicos. Os dois doentes com a forma pseudotumoral que apresentaram melhora eram dependentes do corticóide antes do tratamento com o praziquantel, sendo possivel suspender a corticorterapia após curto periodo de tempo após este tratamento.

Um ano apos o tratamento com praziquantel, 5 doentes $(\mathbf{4 5 , 4 \% )}$ mostraram os testes RIF e ELISA não-reagentes no soro e $3(42,8 \%)$ apresentaram esges testes não-reagentes no LCR (Tabela 3). Um dos doentes que apresentou os testes ainda reagentes no soro, um ano após o tratamento, havia apresentađo esses testes não-reagentes 6 meses após o seu término. Dos 5 enfermos que mostraram as duas reacões imunológicas não-reagentes no soro, um ano ap6s o uso do praziquantel, três tiveram seu quadro clínico melhorado e dols o mantiveram inalterado. Dos três doentes que se tornaram não-reagentes no LCR, dois melhoraram clinicamente e um permaneceu inalterado.

No de pacientes com RIF e ELISA

Após o tratamento

Antes do tratamento

reagente nåo-reagente duvidoso * Total

Soro

reagente

duvidoso*

Total

LCR.

reagente

duvidoso*

Total
4

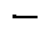

4

2

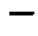

4
5

5

5

2

1

3
1

1

2

2

一

2
10

1

11

6

1

7

Tabela \$ Evolugăo da imunofluorescencia indireta (RIF) e ELISA para cisticercose, no soro e LCR, um ano após o tnatamento com praziquantel. *Duvidoso $=R I F$ ELISA com resultados discordantes.

\section{COMENTARIOS}

Neste estudo, 27 doentes com neurocisticercose foram tratados com o praziquantel, utilizado durante 21 dias, em doses progressivamente crescentes até alcançar $50 \mathrm{mg} / \mathrm{kg} / \mathrm{dia}$. Todos os pacientes usaram associadamente a dexametasona. Foram observadas manifestações clnicas, em maior frequiência e intensidade que as descritas anteriormente 12 , provocando a suspensão do tratamento em $25,9 \%$ dos enfermos. Por ser a neurocisticercose doença com enorme variedade de sintomas, é difícil distinguir os efeitos colaterais das medicaçōes utilizadas no seu tratamento. No presente trabalho, algumas das manifestações clínicas surgidas durante o tratamento podem ter sido consequentes à ação direta da droga no sistema nervoso central (SNC), como: cefaléia, vómitos, confusão mental, convulsões, turvação visual, tonturas, diplopia e disfagia. Outras manifestações clinicas podem ter sido decorrentes do uso da dexametasona, como: polifagia, aumento de peso, retenção hídrica, hipertensão arterial, sindrome de Cushing, acne e psicose. Também devido ao uso do corticóide, podem ter-se exacerbado o herpes-zóster e a conjuntivite viral 22. Os efeitos colaterais, provavelmente relacionados diretamente ao uso do praziquantel, foram: astenia, mialgia, anorexia, emagrecimento, soluços, epigastralgia, pirose, dor abdominal, diarréia, xerostomia, sensaçâoo de frio ou calor, parestesias, insônia, sonolência, prurido nasal, urticária, descamação da pele, polaciúria e taquicardia. Leopold e col.13 e Frobberg 10 relataram que o praziquantel seria inócuo e que as reaçôes adversas, desenvolvidas 
no curso do seu uso, não seriam relacionadas à toxicidade da droga. Estas manifestações seriam decorrentes da reação inflamatória consequente à destruição do parasito e pođeriam ser consideradas confiável sinal de eficácia da medicaçăo 17. Cefaléia, náuseas e convulsōes, embora comuns durante o tratamento, seriam transitórias e melhorariam com analgésicos, anti-eméticos e anticonvulsivantes quando de intensidade leve, ou com corticóides quando severas 17. Entretanto, no presente trabalho, mesmo com a dexametasona usada associadamente em período de tempo maior que o preconizado por outros autores 4,8 , não foi suficiente para corrigir adequadamente a hipertensão intracraniana, que surgiu durante o tratamento com praziquantel em cerca de $1 / 5$ dos pacientes.

Foi descrito que a biotransformação do praziquantel diminui com o aumento de sua dose, possibilitando que, com o seu emprego repetido, atinjam-se taxas teciduais mais altas 17. Também foi mostrado que os niveis sericos do praziquantel ficam reduzidos em cerca de $50 \%$ quando a dexametasona é usada simultaneamente 23 . No presente estudo, um dos pacientes desenvolveu hipertensão intracraniana no primeiro dia do tratamento, logo após a ingestão da segunda dose do praziquantel. O óbito deste paciente provavelmente decorreu de hipertensão intracraniana, consequente à resposta inflamatória pericística. Assim, neste paciente, o praziquantel, em nível sérico bastante inferior ao descrito anteriormente 19, parece ter produzido alterações nos parasitos.

Após um ano do tratamento, cerca de metade dos enfermos apresentou os testes RIF e ELISA não-reagentes no soro e/ou LCR. Neste mesmo período de seguimento, $72 \%$ dos enfermos que completaram o tratamento com o praziquantel apresentaram melhora do quadro clínico. Entretanto, nem sempre houve coincidência da melhora clínica com a apresentação dos testes imunológicos não-reagentes. Também, até o momento atual, não está estabelecido o período de tempo necessário para que as reações imunológicas tornem-se não-reagentes em pacientes não-tratados. Neste estudo, um dos pacientes que se tornou não-reagente 6 meses após o tratamento com praziquantel, voltou a apresentar as reações reagentes um ano após o referido tratamento. Isto demonstra que os testes imunológicos podem ter resultados diversos em diferentes épocas. Portanto, no presente trabalho, não é possivel afirmar que os testes imunológicos não-reagentes, assim como a melhora clínica dos pacientes, sejam consequentes à eficácia do tratamento com o praziquantel. Surgiram alteraçóes laboratorias durante o tratamento com praziquantel associado à dexametasona, sendo a leucocitose a mais frequente. $O$ paciente que apresentou aumento das transaminases tinha sido alcoólatra e poderia ser portador de lesão hepática previamente ao uso do praziquantel, não demonstrada nas provas de função hepática realizadas. Também é possível que houvesse cisticercos no fígado, surgindo, com a administração do praziquantel, resposta inflamatória periscística intra-hepática.

Como $18,5 \%$ dos doentes desenvolveram hipertensão intracraniana durante 0 tratamento, sendo que um deles evoluiu para o óbito provavelmente devido a esta complicação, o uso do praziquantel deve ser feito somente com muita precaução, sob regime de internação e em condições de atendimento de urgência. Devido à grande frequência e gravidade das complicações deste tratamento, os pacientes devem ser avaliados indivjdualmente quanto aos riscos versus os benefícios dele. $O$ doente que apresentar calcificações intracranianas e os testes imunológicos não-reagentes no LCR não deve ser tratado com o praziquantel, pois não há mais atividade da doença 9 . Durante este tratamento, os pacientes epilépticos, com os testes imunológicos reagentes no LCR apresentam frequentemente convulsōes e mesmo estado de mal epiléptico. Portanto, antes de iniciar o praziquantel, deve-se certificar que esses doentes apresentam niveis séricos adequados dos medicamentos anticonvulsivantes. Por apresentarem grave prognóstico, o tratamento com praziquantel é conveniente nos pacientes epilépticos não-controlados com anticonvulsivantes, assim como naqueles doentes com a forma pseudotumoral, que exibem hipertensão intracraniana e são dependentes do corticóide. Os doentes com outras formas de hipertensão intracraniana devem ser analisados individualmente quanto ao risco do uso do praziquantel.

Seria conveniente que se realizassem estudos incluindo-se grupo-controle de doentes não-tratados com drogas, a fim de seguir a evolução natural da doença e definir um guia seguro de tratamento. Há também necessidade de maior conhecimento sobre a ação do praziquantel no cisticerco localizado no SNC do homem, assim como sobre a resposta do hospedeiro ao parasito danificado. 


\section{REFERENCIAS}

1. Botero D, Castano S - Treatment of cysticercosis with proziquantel in Colombia. Am J Trop Med Hyg 31:811, 1982.

2. Carvalho-Filho P, Arruda OM, Melo-Souza SE - Descargas epileptiformes periódicas lateralizadas em neurocisticercose. Arq Neuro-Psiquiat (Săn) Paulo) 47:94, 1989.

3. Chavarria M, González DD - Droncit en el tratamiento de la cisticercosis porcina. Esp Vet $1: 159,1978$.

4. Ciferri F - Praziquantel for cysticercosis of the brain psrenchyma (letter). N Eng J Med 311:733, 1984.

5. Colli BO, Martelli N, Assirati JA Jr, Machado HR, Guerreiro NE, Belluci A - Forma tumoral da neurocisticercose: exérese de cisticerco de $70 \times 77 \mathrm{~mm}$ e tratamento com praziquantel. Relato de caso. Arq Neuro-Psiquiat (Sīo I'aulo) 42:158, 1984.

6. Costa JM - Teste imunoenzimático (EIISA) no diagnóstico da neurocisticercose. Tese. Instituto de Ciências Biomédicas, Universidade de São Paulo. São Paulo, 1983.

7. DeGhetaldi LD, Norman RM, Douville AW Jr - Cerebral cysticercosis treâted biphasically with dexamethasone and praziquantel. Ann Intern Med 99:179, 1983.

8. DeGhetaldi LD, Norman RM, Doliville AW Jr - Praziquantel for cysticercosis of the brain parenchyma (letter), N Eng J Med 311:732, 1984.

9. DelBrutto OH, Sotelo J - Neurocysticercosis: an uydate. Rev Infect Dis 10:1075, 1988.

10. Frobberg H - Propriedades farmacocinéticas, farmacológicas y toxicológicas del praziquantel. Salud Publ Méx 24:605, 1982.

11. Gómez JG, Pena G, Patino R, Pradilha G - Neurocysticercosis treated with prazfquantel. Neurologia en Colombja 5:665, 1981.

12. Groll EW $\rightarrow$ Chemotherapy of human cysticercosis with praziquantel. In Flisser A et al (eds): Cysticercosis: Present State of Knowledge and Perspectives. Academic Press, New York, 1982, pg 207.

13. Leopold G, Ungethüm W, Groll $\mathbf{H}$, Diekmann HW, Nowak H, Wegner DHG - Clinical pharmacology in normal volunteers of praziquantel, a new diug aggainst schistosomes and cestodes: an example of complex study covering both tolerance and pharmacokinetics. Eur J Clin Pharmacol 14:281, 1978.

14. Machado AJ, Camargo ME, Hoshino S - Reação de imunofluorescência para a cisticercose com particulas de Cysticercus cellulosae fixadas a lâminas de microscopia. Rev Soc Med Trop $7: 181,1973$.

15. Rim HJ, Won CR, Chu JW - Studies on the human cysticercosis and its therapeutic trial with praziquantel (Embay 3440). Korea Univ Med J 17:459, 1980.

16. Robles C, Chavarria $M$ - Un caso de cisticercosis cerebral curado medicamente. Gaceta Méd Mex 116:65, 1980.

17. Sotelo J, Escobedo F, Rodriguez-Carbajal J, Torres B, Rubio-Donnadieu F - Therapy of parenchymal brain cysticercosis with praziquantel. N Eltgl J Med 310:1001, 1984.

18. Spina-França A, Nöbrega JPS - Neurocisticercose e praziquantel. Rev Paul Med 95:34, 1980.

19. Spina-França A, Nóbrega JPS, Livramento JA, Machado LR - Administration of praziquantel in neurocysticercosis. Trompenmed Parasit 33:1, 1982.

20. Thomas $\mathrm{H}$ - Resultados experimentales con praziquantel (Embay 8440) en cestodiasis $\mathrm{y}$ cisticercosis. Bol Chil Parasitol 32:2, 1977.

21. Thomas $H$, Andrews $P$, Mehlhorn $H-$ New result on the effect of praziquantel in experimental cysticercosjs. In Papers Read at Workshop: Praziquantel in Human Cysticercosis. México, 1981.

22. Thorn GW - Clinical considerations in the use of corticosteroids. N Engl J Med 274:775, 1966.

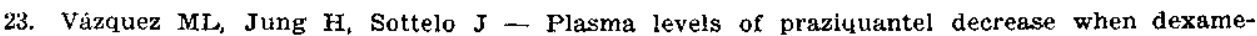
thasone is given simultaneously. Neurology $37: 1561,1987$. 